\title{
Características sensoriais e físicas de extratos e tofus de soja comum processada termicamente e livre de lipoxigenase
}

\author{
Sensorial and physical characteristics of bleached
} and lipoxygenase-free soybean milk and curd

\author{
Sueli CIABOTTI ${ }^{1 *}$, Maria de Fátima Píccolo BARCELOS ${ }^{2}$, Ana Carla Marques PINHEIRO ${ }^{1}$, \\ Paulo Roberto CLEMENTE ${ }^{3}$, Maria Aparecida Correa LIMA ${ }^{3}$
}

\begin{abstract}
Resumo
O objetivo deste trabalho foi selecionar o processo de obtenção de extrato de soja e respectivo tofu, obtidos com a soja comum (BRS 133), soja comum submetida ao processo de branqueamento (BRS 133) e soja comum livre de lipoxigenase (BRS 213), verificando a influência do branqueamento dos grãos de soja comum, anterior à sua maceração, nas características sensoriais e físicas destes produtos. O processamento térmico (branqueamento dos grãos) a que a soja comum foi submetida mostrou-se imprescindível para tornar o "sabor" do extrato de soja mais agradável ao paladar dos provadores, não interferindo na sua aparência e nem na cor, tendo sempre como referência a soja livre de lipoxigenase, porém o branqueamento, por sua vez, depreciou não só o "sabor", mas também a "textura" e a "aparência" dos respectivos tofus, mostrando-se indiferente para o aspecto sensorial "cor". Na avaliação pelo método instrumental da cor e da textura dos tofus obtidos de soja comum branqueada houve diferenças significativas.

Palavras-chave: branqueamento; sabor; textura; aparência; cor
\end{abstract}

\begin{abstract}
The overall objective of this study was to select a process for producing soybean milk and curd (tofu) that results in a pleasant-tasting product. The specific objective was to ascertain how bleaching and nonbleaching of conventional soybeans, prior to soaking, affects the physical and sensorial characteristics of the soymilk and tofu, and to compare the color, taste, appearance and texture of soymilk and tofu obtained from unbleached soybeans (BRS 133 cultivar), from bleached soybeans (BRS 133 cultivar), and from lipoxygenase-free soybeans (BRS 213 cultivar). The bleaching process was found to be indispensable to enhance the flavor of soybean milk. Bleaching did not affect the appearance or color of soybean milk in comparison with lipoxygenase-free soybean milk, but the used of bleached soybeans negatively affected the flavor, texture and appearance of tofu, although its color was not affected.

Keywords: bleaching; flavor; texture; appearance; color.
\end{abstract}

\section{Introdução}

Dentro da versatilidade da soja [Glycine $\max ($ L.) Merrill] no campo da indústria de alimentos, são conhecidos e comercializados, além da soja em grãos, farinha de soja, concentrados e isolados de soja, soja texturizada, alimentos fermentados como miso, shoyo, tempeh, e ainda, o extrato de soja ou leite de soja (soymilk), comercializado em vários sabores. Desse extrato, fabrica-se o tofu, além de outros produtos.

O tofu é o produto obtido da precipitação das proteínas, pela adição de coagulante, dentre os utilizados tem-se o glucona- $\delta$-lactona, ou outros, produzindo um gel resultante da formação de uma rede protéica com retenção de água, lipídeos e outros constituintes. Sua textura é lisa, macia e elástica ${ }^{21}$, sendo importante fonte de proteína, minerais e vitaminas, ao mesmo tempo em que apresenta baixa proporção de gorduras saturadas e ausência total de colesterol. Como alimento sau-

Recebido para publicação em 10/11/2006

Aceito para publicação em 29/5/2007 (002054)

${ }^{1}$ Departamento de Ciência dos Alimentos - DCA,

Universidade Federal de Lavras - UFLA,

CP 37, CEP 37200-000, Lavras - MG, Brasil,

E-mail: sueliciabotti@terra.com.br

Laboratório de Bioquímica Nutricional,

Departamento de Ciência dos Alimentos - DCA

Universidade Federal de Lavras - UFLA, Lavras - MG, Brasil

Laboratório de Análise Sensorial

Departamento de Ciência dos Alimentos - DCA

Universidade Federal de Lavras - UFLA, Lavras - MG, Brasil

*A quem a correspondência deve ser enviada dável, de alto valor nutritivo e de custo reduzido, o tofu, tem sido utilizado não raramente em preparações alimentícias, em substituição de ovos, queijos, carnes e outros alimentos de origem animal.

Os sabores e odores desagradáveis (offflavor) dos produtos da soja são atribuídos à ação das enzimas lipoxigenases formando hidroperóxidos dos ácidos graxos poliinsaturados ${ }^{16}$. Trabalhos têm sido conduzidos no melhoramento genético da soja, para reduzir a ação das lipoxigenases, e medidas tecnológicas foram propostas como o processamento térmico dos grãos especificamente o branqueamento para inativar as lipoxigenase $\mathrm{s}^{13,14}$, podendo assim aumentar a aceitabilidade da soja e de seus produtos.

Diante do exposto, este trabalho tem por objetivos avaliar os extratos de soja e respectivos tofus, produzidos com soja comum, soja comum branqueada e comum livre de lipoxigenase, nas características sensoriais no que se referem a sabor, textura, aparência e cor destes produtos e as características físicas de textura e cor utilizando método instrumental.

\section{Material e métodos}

O trabalho foi conduzido no Departamento de Ciência dos Alimentos da Universidade Federal de Lavras. A soja [Glycine max (L.) Merrill] cultivar BRS 133 e a variedade BRS - 213, livre de lipoxigenase - lipoxigenase I, lipoxigenase II 
e lipoxigenase III, foram cedidas pela Empresa Brasileira de Pesquisa Agropecuária - Embrapa-Soja - PR.

A Figura 1 apresenta o fluxograma dos procedimentos gerais do trabalho.

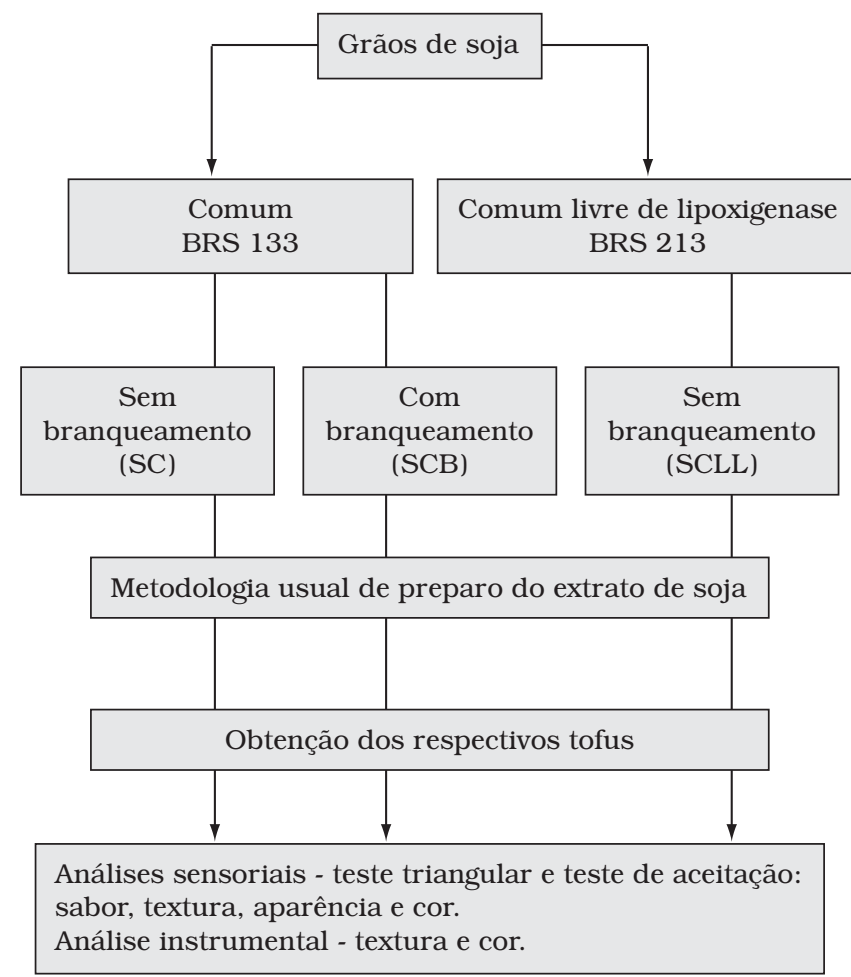

Figura 1. Fluxograma geral da produção do extrato de soja e respectivos tofus e das análises realizadas.

\subsection{Obtenção dos extratos de soja (leite de soja) e tofus}

Inicialmente foram obtidos os extratos de soja (leite de soja) originados de três tratamentos: soja comum (SC) pela metodologia usual (tratamento 1); soja comum branqueada (SCB) pela metodologia usual, porém com uma modificação no início do processo, no qual os grãos foram submetidos ao branqueamento (tratamento 2); soja comum livre de lipoxigenase (SCLL) pela metodologia usual, ou seja, sem branqueamento (tratamento 3).

O método usual para a obtenção do extrato de soja (leite de soja) obedeceu a proporção de soja: água em 1:10, ou seja, $100 \mathrm{~g}$ de soja para 1 litro de água ${ }^{7,21}$.

Após seleção e pesagem, os grãos foram lavados e hidratados durante 12 horas à temperatura ambiente (aproximadamente $23^{\circ} \mathrm{C}$ ). Depois da maceração e da drenagem da água, os grãos foram triturados. Posteriormente, a mistura foi filtrada e o extrato foi submetido a aquecimento ( 95 a $98^{\circ} \mathrm{C} / 5$ minutos) e correção do volume final para $1 \mathrm{~L}$. Desta forma obtiveram-se os tratamentos 1 e 3, utilizando-se a SC e a SCLL, respectivamente.

Utilizando-se a metodologia usual da obtenção, após a seleção e pesagem da soja, ocorreu o branqueamento dos grãos com água em ebulição por 5 minutos e, em seguida, o resfriamento e condução dos grãos para a maceração por 12 horas, sendo que os demais procedimentos foram idênticos à técnica descrita anteriormente. Desta forma, obteve-se o tratamento 2 deste trabalho.

Para a obtenção dos tofus, os extratos de soja foram resfriados até $75-80^{\circ} \mathrm{C}$ e a cada litro de extrato de soja adicionaramse dois gramas de glucona- $\delta$-lactona - GDL, (Sigma Chemical, Louis, USA) diluídos em $20 \mathrm{~mL}$ de água destilada, usados como agente coagulante para formação da coalhada. Depois de 10 minutos, foram efetuados os cortes da coalhada e colocados em formas de polietileno com dessorador e, prensados ainda quentes, em torno de uma hora e meia com peso de 14 g. $\mathrm{cm}^{-2}$ e resfriados $\left(5^{\circ} \mathrm{C}\right.$ por 4 horas).

\subsection{Avaliação sensorial do extrato de soja e tofu}

Através de contato pessoal, 24 provadores entre funcionários e alunos de pós-graduação, com experiência sensorial, foram recrutados levando-se em consideração o interesse, disponibilidade, familiaridade com os produtos a serem testados e boa saúde ${ }^{1}$.

Após o recrutamento, realizou-se a seleção e treinamento dos provadores aplicando-se o Teste Triangular ${ }^{11}$, com extrato de soja em diferentes concentrações, alterando gradativamente o grau de diferença de grande para pequeno ${ }^{1}$. As concentrações dos extratos de soja (leite de soja) utilizadas nos testes com grau de diferença grande, foram de proporção soja:água de 1:6 e 1:12. Para avaliar o grau de diferença moderada, utilizaram-se as proporções 1:8 e 1:10 e para avaliar o grau de diferença pequena utilizaram-se as proporções de 1:9 e 1:10. Cada provador recebeu 2 pares de amostras das 6 combinações possíveis, respeitando-se o balanceamento (as amostras aparecem em igual número de vezes nas diferentes posições possíveis), com o total de 12 respostas por provador ${ }^{4}$. Foram selecionados os provadores que obtiveram $\geq$ a $60 \%$ de respostas corretas. Desta forma, foram selecionados 12 provadores.

As amostras dos extratos de soja, com os respectivos tofus, obtidas dos três tratamentos (soja comum - SC, soja comum branqueada - SCB e soja comum livre de lipoxigenase - SCLL) foram avaliadas sensorialmente pelo Teste Triangular conforme MEILGAARD, CIVILLE e CARR ${ }^{11}$, por doze provadores selecionados, os quais realizaram os testes em três repetições (36 respostas). Utilizou-se o Teste Triangular para comparar a diferença entre os tratamentos das seguintes combinações: soja comum $x$ soja comum branqueada; soja comum $x$ soja comum livre de lipoxigenase e soja comum branqueada $x$ soja comum livre de lipoxigenase. O teste baseou-se em apresentar ao provador simultaneamente três amostras, sendo duas iguais e uma diferente, avaliando-as em cabines individuais, iluminadas com luz verde de baixa intensidade. As amostras foram avaliadas à temperatura de $23{ }^{\circ} \mathrm{C}$ em quantidades de $30 \mathrm{~mL}$ para o extrato de soja (leite de soja) e em cubos de $1,5 \mathrm{~cm}$ cortados uniformemente para os testes com o tofu. As amostras foram oferecidas em recipientes descartáveis de cor branca, dotados de suportes codificados com três dígitos numéricos. Para o teste de aparência e cor dos tofus e extratos de soja, as amostras foram apresentadas simultaneamente em 
uma única cabine, com iluminação branca, em recipientes de vidro transparente (incolor) e identificadas com códigos de três dígitos.

A análise ou interpretação dos resultados baseou-se no número de acertos (número de respostas corretas) e, para tanto, consultou-se a tabela de "número mínimo de respostas corretas para estabelecer diferença significativa entre as amostras em vários níveis de significância”, conforme O'MAHONY ${ }^{15}$.

Em seguida ao Teste Triangular, aplicou-se, em cabines individuais nas mesmas condições descritas anteriormente, o Teste de Aceitabilidade utilizando-se a escala hedônica estruturada mista de 9 pontos entre 1 (desgostei muitíssimo) e 9 (gostei muitíssimo) para avaliar sabor, cor e aparência dos extratos de soja e as mesmas características para o tofu, incluindo a textura ${ }^{4}$.

Da equipe de provadores não treinados para o Teste de Aceitabilidade, foram obtidas trinta e três respostas.

No experimento, utilizou-se o delineamento em blocos completos casualizados. Realizou-se análise de variância (ANOVA) e quando os efeitos dos tratamentos foram significativos ( $\mathrm{p}<0,05 \%$ ) utilizou-se o teste SCOTH KNOT ${ }^{18}$. As análises de variância e teste de médias foram realizadas segundo técnicas usuais do software SISVAR $^{3}$.

\subsection{Avaliação instrumental de cor e textura do tofu}

\section{Cor do tofu}

A cor do tofu foi determinada pelo colorímetro marca Minolta, modelo Chroma Meter CR-3000, sistema L*a*b CIELAB. Os parâmetros de cor, medidos em relação à placa de cor branca, foram:

- $\mathrm{L}=$ luminosidade $(0=$ cor preta a $100=$ cor branca $)$;

- $\mathrm{a}=$ variando da cor verde ao vermelho $(-60,0 \mathrm{a}+60,0$, respectivamente); e

- $\mathrm{b}=$ variando da cor azul ao amarelo $(-60,0$ a +60,0, respectivamente).

\section{Textura do tofu}

Foi realizado o teste de análise do perfil de textura (TPA) do tofu (em cubos). Utilizou-se o Texturômetro Stable Micro System modelo TAXT2i com uma probe cilíndrica de alumínio com $20 \mathrm{~mm}$ de diâmetro, com extremidade plana. Os pedaços de tofus foram cortados em cubos de $10 \mathrm{~mm}$.

Foi analisada a firmeza do primeiro ciclo de compressão, sendo expresso em N. Foi configurada uma compressão de $7,5 \mathrm{~mm}$, correspondente a uma deformação de $75 \%$ da amostra. Os parâmetros de configuração do aparelho foram:

- velocidade do pré-teste $=4,0 \mathrm{~mm} / \mathrm{s}$;

- velocidade do pós-teste $=2,0 \mathrm{~mm} / \mathrm{s}$;

- força $=0,196 \mathrm{~N}$;

- tempo $=5,00 \mathrm{~s}$;
- distância de compressão $=7,5 \mathrm{~mm}$; e

- velocidade do teste $=1,0 \mathrm{~mm} / \mathrm{s}$.

\section{Resultados e discussão}

\subsection{Avaliação sensorial}

De acordo com a tabela do teste triangular ${ }^{4}$, para um total de 36 respostas, são necessárias no mínimo 18 respostas corretas $(\mathrm{p}<0,05)$ para estabelecer diferença significativa entre as amostras. Pelo Teste Triangular ${ }^{11}$ entre os extratos de soja (leite de soja) obtidos de soja comum (SC) e o de soja comum branqueada (SCB), no qual se obtiveram 29 respostas corretas, detectou-se diferença significativa ( $p<0,001$ ), fato este atribuído ao calor a que foram submetidos os grãos num tempo pré-determinado (branqueamento), ocasionando a inativação das enzimas lipoxigenases, responsáveis pela propagação de compostos que dão origem aos sabores indesejáveis da soja.

Observou-se, pelo Teste triangular quanto aos aspectos sensoriais, diferença significativa $(\mathrm{p}<0,001)$ entre o extrato de soja obtido de soja comum (SC) e o livre de lipoxigenase (SCLL), no qual se obtiveram 23 respostas corretas, diferença esta, supostamente ocasionada pela presença e ação das enzimas lipoxigenases nos grãos de SC, causando no produto sabor e odor indesejáveis. Por outro lado, a ausência da enzima lipoxigenase nos grãos da SCLL, proporcionou sabor mais agradável no extrato obtido com este cultivar, o qual foi confirmado no teste de aceitação (Tabela 1).

Estabeleceu-se diferença ( $\mathrm{p}<0,001$ ) sensorial também pelo teste triangular, entre o extrato de soja preparado do grão livre de lipoxigenase (SCLL) e o extrato de soja comum branqueada (SCB), com 25 respostas corretas. A redução da ação da lipoxigenase pelo uso do calor (branqueamento) aplicado aos grãos na etapa preliminar de sua elaboração, provavelmente interferiu em algumas características físicas das proteínas do extrato, o que pode ter alterado de certa forma, as características sensoriais do extrato de SCB. Segundo WOLF e COWAN ${ }^{23}$, o calor adicional na soja e produtos pode interferir na solubilidade das proteínas e, conseqüentemente, neste trabalho, o calor na etapa inicial da obtenção do extrato de soja, pode ter alterado o sabor do produto final.

Os valores médios (escores) obtidos pelo teste de aceitabilidade foram verificados na Tabela 1 em relação às características de sabor, aparência e cor do extrato de soja.

Tabela 1. Valores médios dos escores* de aceitação dos extratos de soja produzidos com soja comum (SC), soja comum branqueada (SCB) e soja comum livre de lipoxigenase (SCLL).

\begin{tabular}{lrcc}
\hline Extrato de soja & \multicolumn{3}{c}{${ }^{*}$ Escores de 1 a 9} \\
\cline { 2 - 4 } & Sabor & Aparência & Cor \\
\hline SC & $6,24^{\mathrm{b}}$ & $7,45^{\mathrm{a}}$ & $7,55^{\mathrm{a}}$ \\
SCB & $7,44^{\mathrm{a}}$ & $7,70^{\mathrm{a}}$ & $7,72^{\mathrm{a}}$ \\
SCLL & $7,61^{\mathrm{a}}$ & $7,70^{\mathrm{a}}$ & $7,29^{\mathrm{a}}$ \\
C. V. (\%) & 10,17 & 9,68 & 9,73 \\
\hline
\end{tabular}

*Escores: 1 = desgostei muitíssimo; $2=$ desgostei muito; $3=$ desgostei moderadamente; $4=$ desgostei ligeiramente; 5 = indiferente; 6 = gostei ligeiramente; 7 = gostei moderadamente; 8 = gostei muito; e 9 = gostei muitíssimo. Médias nas colunas seguidas por letras iguais não diferem entre si a 0,05 de significância (Scott Knott). 
As notas atribuídas pelos consumidores, ao sabor dos extratos de soja obtidos com a soja comum branqueada (SCB) $\left(98{ }^{\circ} \mathrm{C} / 5\right.$ minutos) e os obtidos de soja comum livre de lipoxigenase (SCLL) foram melhores aceitos, diferindo significativamente $(\mathrm{p}<0,05)$ do extrato obtido com a soja comum (SC) sem branqueamento, fato este provavelmente devido à inativação da lipoxigenase com o calor (branqueamento), na etapa inicial, frente ao extrato de soja, obtido de um cultivar com a supressão do gene da lipoxigenase (SCLL), responsáveis pelo desenvolvimento do sabor desagradável dos extratos. Embora tenha existido diferença sensorial significativa dos extratos de soja, detectada pelo Teste Triangular (realizado por provadores treinados e familiarizados com o produto), entre os extratos de soja comum branqueada e o livre de lipoxigenase, pelo Teste de Aceitação não foi detectada diferença significativa entre os respectivos extratos de soja (Tabela 1 ).

TORRES-PENARANDA e REITMEIER ${ }^{20}$, estudando o sabor dos extratos de soja obtidos de soja comum (SC) e soja comum livre de lipoxigenase (SCLL), verificaram diferenças em quase todos os atributos de sabor. Em outro estudo com SC e SCLL para obtenção de extratos de soja de TORRES-PENARANDA et al. ${ }^{19}$, foi verificada, nos extratos de soja obtidos de SCLL, menor intensidade para o sabor de "feijão cru", pelos provadores americanos do que pelos chineses quando comparados ao extrato de soja obtido de SC, ao passo que os japoneses não encontraram diferença alguma entre ambos os extratos.

Pelo Teste Triangular do tofu, não se observou diferença sensorial significativa entre o tofu produzido com soja comum (SC) e o obtido de soja comum livre de lipoxigenase (SCLL), no qual se obtiveram apenas 16 respostas corretas. A remoção do soro durante o processamento de tofu com a soja comum provavelmente contribuiu para a eliminação dos compostos hidrossolúveis que ocasionam os sabores indesejáveis ${ }^{19}$, justificando a não existência de diferenças entre estes dois produtos.

O Teste Triangular aplicado ao tofu obtido da soja comum branqueada (SCB) mostrou diferença sensorial de forma significativa ( $p<0,001$ ) do tofu obtido da SCLL, com 29 acertos, e do obtido com a soja comum, com 34 respostas corretas, podendo-se atribuir, no caso, o fato das proteínas da soja com o aquecimento adicional (branqueamento dos grãos na etapa inicial) terem causado mudanças químicas indesejáveis no produto, interferindo na qualidade sensorial do tofu. KWORK et al. ${ }^{7}$ relataram que as proteínas são facilmente desnaturadas pelo calor que, como conseqüência, altera a conformação das moléculas, depreciando as características do produto, causando escurecimento e o desenvolvimento de "sabor cozido", o que pode explicar esta diferença no tofu obtido com a soja submetida ao branqueamento.

Na Tabela 2, são apresentados os valores (escores) obtidos no Teste de Aceitabilidade em relação às características de sabor, textura, aparência e cor dos tofus.

Os tofus obtidos com soja comum e soja comum livre de lipoxigenases não apresentaram diferença significativa $(\mathrm{p}>0,05)$ nas características de sabor, textura, aparência e cor, e também na maior aceitabilidade destes atributos.
Tabela 2. Valores médios dos escores* de aceitação dos tofus produzidos com soja comum (SC), soja comum branqueada (SCB) e soja comum livre de lipoxigenase (SCLL).

\begin{tabular}{lcccc}
\hline \multirow{2}{*}{ Tofu } & \multicolumn{4}{c}{${ }^{*}$ Escores de 1 a 9 } \\
\cline { 2 - 5 } & Sabor & Textura & Aparência & Cor \\
\hline SC & $7,59^{\mathrm{a}}$ & $7,77^{\mathrm{a}}$ & $7,68^{\mathrm{a}}$ & $7,99^{\mathrm{a}}$ \\
SCB & $5,43^{\mathrm{b}}$ & $5,15^{\mathrm{b}}$ & $5,94^{\mathrm{b}}$ & $7,46^{\mathrm{a}}$ \\
SCLL & $7,88^{\mathrm{a}}$ & $7,81^{\mathrm{a}}$ & $7,95^{\mathrm{a}}$ & $7,81^{\mathrm{a}}$ \\
C. V. (\%) & 12,96 & 13,86 & 8,60 & 6,63 \\
\hline
\end{tabular}

*Escores: 1 = desgostei muitíssimo; $2=$ desgostei muito; $3=$ desgostei moderadamente 4 = desgostei ligeiramente; 5 = Indiferente; 6 = gostei ligeiramente; 7 = gostei moderadamente; 8 = gostei muito; e 9 = gostei muitíssimo. Médias nas colunas seguidas por letras iguais não diferem entre si a 0,05 de significância (Scott Knott).

O tofu obtido da soja comum branqueada apresentou menor aceitabilidade do que os demais tratamentos, para sabor, textura e aparência (Tabela 2), devido à ação do calor (branqueamento dos grãos $-98^{\circ} \mathrm{C} / 5$ segundos, seguido de resfriamento), justificando a diferença detectada no Teste Triangular. Vale salientar que neste trabalho o branqueamento foi considerado um tratamento térmico adicional (além do convencional), porém não excessivo, pois o processamento térmico nos produtos de soja é necessário para, além de reduzir e/ou eliminar os fatores antinutricionais, melhorar a digestibilidade das proteínas ${ }^{9,10}$. Não se deve, portanto, incluir a etapa do branqueamento na obtenção do extrato de soja quando este se destina à fabricação do tofu, pois a ação do calor nos grãos, antes da maceração, altera alguns componentes responsáveis pelo sabor característico, além da ação pretendida que seria a inativação da lipoxigenase. O tratamento térmico adicional (branqueamento), aplicado inicialmente nos grãos para obtenção do tofu, embora tenha depreciado o sabor do produto, interferiu na textura, com obtenção de um produto menos firme, e na aparência, quando comparados aos demais tratamentos, sendo importante colocar que a cor não foi alterada.

Em trabalho realizado por TORRES-PENARANDA et al. ${ }^{19}$, foi verificado que os americanos e chineses não encontraram diferença em determinadas características sensoriais dos tofus obtidos de soja comum e comum livre de lipoxigenase; porém, os japoneses classificaram os tofus da soja livre de lipoxigenase como de sabores mais suaves do que os obtidos de soja comum.

\subsection{Avaliação instrumental de cor e textura do tofu}

Na Tabela 3, observam-se os valores médios da leitura da cor dos tofus medidas pelo sistema "CIELAB", e a força obtida após a compressão de $75 \%$ de deformação dos tofus.

Tabela 3. Valores médios de cor dos tofus medida pelo sistema "CIELAB" e força obtido após aplicação de compressão de 75\% de deformação dos tofus produzidos com soja comum (SC), soja comum branqueada (SCB) e soja comum livre de lipoxigenase (SCLL).

\begin{tabular}{ccccc}
\hline \multirow{2}{*}{ Tratamentos } & \multicolumn{3}{c}{ Tofus analisados } \\
\cline { 2 - 3 } \cline { 2 - 3 } & \multicolumn{2}{c}{ Pontuação “CIELAB” } & Textura \\
\cline { 2 - 3 } SC & $84,81^{\mathrm{a}}$ & $11,08^{\mathrm{c}}$ & & \multicolumn{2}{c}{ Força (N) } \\
SCB & $85,14^{\mathrm{a}}$ & $11,85^{\mathrm{a}}$ & \\
SCLL & $84,69^{\mathrm{a}}$ & $12,99^{\mathrm{a}}$ & $3,78^{\mathrm{b}}$ \\
CV (\%) & 1,17 & & $3,36^{\mathrm{b}}$ \\
\hline
\end{tabular}

Médias nas colunas seguidas por letras iguais não diferem entre si a 0,05 de significância (Scott Knott). 
A cor característica do tofu normalmente expressa a qualidade do produto e varia entre o branco e o amarelo-claro.Todas as amostras apresentaram coloração entre os padrões; a luminosidade (L) não apresentou diferença significativa $(p>0,05)$ entre os tratamentos. A intensidade do amarelo (b) nos tofus diferiu significamente entre os três tratamentos. O tofu produzido de soja comum livre de lipoxigenases (SCLL) apresentou valor mais elevado para cor amarela, seguido do tofu obtido de soja comum branqueada (SCB) e do obtido com a soja comum (SC). No tofu obtido com a mesma soja, porém submetido ao branqueamento, apresentou para a cor amarela leitura de 11,85, diferindo do obtido da soja comum $(11,08)$. Provavelmente o que contribuiu para esta diferença de cor foi o começo de reação de Maillard pela ação do tratamento térmico adicional (branqueamento), no qual pesquisas relatam resultados semelhantes de intensificação da cor amarela em outros produtos de soja ${ }^{2,7}$, sendo atribuído à ocorrência da referida reação.

Uma série de fatores explica a diferença de cor entre os grãos de soja e seus produtos finais. Reações enzimáticas e não-enzimáticas em grãos de soja são aceleradas quando são estocadas a temperaturas baixas e/ou muito elevadas e os pigmentos escuros formados são transferidos para o extrato de soja e tofu ${ }^{8}$, além do genótipo dos grãos ${ }^{2}$.

KARIN et al. ${ }^{6}$ apresentaram os valores médios da cor de tofus obtidos com a ação de glucona- $\delta$-lactona próximos aos apresentados na Tabela $3 \mathrm{com}$ as leituras médias de luminosidade (L) de 82,51, os valores do amarelo 13,01.

Embora no teste sensorial de aceitação não se tenha detectado diferença entre a cor dos tofus obtidos nas diferentes condições deste estudo, na avaliação instrumental (colorímetro) esta diferença foi significativa.

O tofu obtido de soja comum (SC) apresentou maior resistência à compressão valor de 4,31 (Tabela 3), apresentando diferença significativa $(\mathrm{p}<0,05)$ com relação aos tofus obtidos de soja comum branqueada (SCB) e de soja comum livre de lipoxigenase (SCLL) com valores de 3,78 e 3,36, respectivamente. A textura do tofu de soja comum branqueada foi influenciada pelo branqueamento, comparativamente com o tofu de soja comum sem o branqueamento, pois este último apresentou-se com maior firmeza. Como o branqueamento foi um tratamento adicional, aplicado a um mesmo cultivar de soja, estes resultados seguiram semelhantes tendências quando comparados às respostas do Teste de Aceitação discutido no item interior, o qual mostrou existir diferença entre a textura nestes dois produtos.

As proteínas têm um papel fundamental na formação da rede tridimensional da coalhada na produção do tofu, ocorrendo uma diferença acentuada entre as propriedades físicas e o gel de tofu feito de globulina 7 e 11S. O gel do tofu com globulinas $11 \mathrm{~S}$ (glicinina) é estabilizado por ligações disulfídricas $^{5,12}$, que são ligações mais fortes, o que pode ser explicado talvez pelo fato de predominar esse tipo de ligações no tofu obtido de soja comum (SC), conferindo, assim, mais firmeza. O tofu de soja branqueada apresentou-se menos firme. Possivelmente o branqueamento aplicado nos grãos de soja ocasionou uma modificação na conformação das moléculas de proteína (desnaturação), dificultando a ocorrência de ligações mais sustentáveis da rede protéica, não permitindo a obtenção de tofu com características adequadas de textura.

A desnaturação térmica influi nas propriedades físicas de geleificação, texturização ou fibrilação das proteínas ${ }^{12}$, provocando a formação de uma rede tridimensional mais fraca e com retenção de umidade desuniforme na sua estrutura ${ }^{22}$.

Embora a resistência à compressão do tofu obtido com a soja livre de lipoxigenase tenha sido diferente estatisticamente a do tofu de soja comum, esta deve-se, provavelmente à composição química dos grãos SC e SLL, e não à alteração ocasionada pelo calor, que afetasse a formação da rede tridimensional. Desta forma, no teste de aceitação, os resultados de textura do tofu de SC e SLL foram iguais e mais bem aceitos do que o de SCB.

\section{Conclusões}

De acordo com os resultados do Teste de Aceitação, o melhor sabor do extrato de soja (leite de soja) foi obtido tanto com a SCLL, quanto com a SCB, porém o extrato de soja destinado a fabricação do tofu não deve ser obtido de soja que tenha sido submetida ao branqueamento, pois este tratamento adicional prejudicou os atributos de sabor, textura e aparência do tofu. O melhor sabor do tofu foi obtido tanto com soja comum (sem branqueamento), quanto de soja comum livre de lipoxigenase (SCLL). O melhoramento genético dos grãos de soja, visando melhoria do sabor, torna-se dispensável para a obtenção do extrato de soja e tofu.

Na avaliação instrumental, os tofus obtidos da soja comum livre de lipoxigenase apresentaram maior intensidade de cor amarela e menor firmeza. Os tofus obtidos da soja comum branqueada apresentaram maior intensidade de cor amarela e também menor firmeza, quando comparados aos tofus obtidos da soja comum.

\section{Referências bibliográficas}

1. AMERICAN SOCIETY FOR TESTING AND MATERIALS. Guidelines for the selection and training of sensory panel members. Philadelphia: ASTM, 1981. p. 35.

2. BHARDWAJ, H. L. et al. Yield and quality of soymilk and tofu made from soybean genotypes grown at four locations. Crop Science, Madison, v. 39, n. 2, p. 401-405, Mar./Apr. 1999.

3. FERREIRA, D. F. Análise estatística por meio do SISVAR para Windows versão 4. 0. In: REUNIAO ANUAL DA REGIÃO BRASILEIRA DA SOCIEDADE INTERNACIONAL DE BIOMETRIA. UFSCar, 45, 200, São Carlos. Anais... São Carlos: UFSCar, 2000. p. $255-258$.

4. FERREIRA, V. L. P. et al. Análise sensorial: testes discriminativos e afetivos. Campinas: SBCTA, 2000. 127 p. (Manual: série qualidade)

5. FUKUSHIMA, D. Deterioratie changes of proteins during soybean food processing and their use in foods. In: Chemical deterioration of proteins. Washington: American chemical society, 1980. cap. 10, p. 211-239.

6. KARIM, A. A. et al. Effect of carrageenan on yield and propertirs of tofu. Food Chemistry, Oxford, v. 66, n. 2, p. 159-165, Aug. 1999. 
7. KWOK, K. C.; MACDOUGALL, D. B.; NIRANJAM, K. Reaction kinectcs of heat-induced colour changes in soymilk. Journal of Food Engineering, Oxford, v. 40, n. 1, p. 15-20, Jan. 1999.

8. LAMBRECHT, H. S. et al. Effect of soybean storage on tofu and soymilk production. Journal of Food Quality, Trumbull, v. 19, n. 3, p. 189-202, June 1996.

9 LIENER, I. E. Toxic constituents of plant foodstuffs. New York: Academic Press, 1969, 500 p.

10. LIENER, I. E. Implications of antinutritional components in soybeans foods. Critical Reviews in Food Science and Nutrition, Cleveland, v. 34, n. 1, p. 31-67, 1994.

11. MEILGAARD, M.; CIVILLE, G. V.; CARR, B. T. Sensory evaluation techniques. 2. ed. Florida - USA: CRC Press, 1991. 354 p.

12. MUJOO, R.; TRINH, D. T.; PERRY, K. W. Characterization of storage proteins in different soybean varieties and their relationship to tofu yield and texture. Food Chemistry, Oxford, v. 82, n. 2, p. 265-273, Aug. 2003.

13. NELSON, A. I.; STEINBERG, M. P; WEI, S. L. Illinois process for preparation of soymilk. Journal of food science. Chicago, v. 41, n. $1,1976$.

14. OKUBO, K. et al.; Components responsible for the undesirable taste of soybean seeds. Biosci. Biotech. Biochem., v. 56, n. 1, p. 99-103, 1992.

15. O'MAHONY, M. Sensory evaluation of food. Statistical methods and procedures. Marcel Dekker Inc., New York: Marcel Dekker, 1986. 487 p.
16. RACKIS, J. J.; SESSA, D. J; HONIG, D. H. Flavor problems of vegetable food proteins. J. Amer. Oil chem., San Diego, v. 56, n. 6, p. 262-271, 1979.

17. SAWAZAKI, H. E.; TEIXEIRA, J. P. F.; MIRANDA, M. A. C. Avaliação da atividade da lipoxigenase em linhagem de soja. Bragantia, Campinas, v. 46, n. 2, p. 371-380, 1987.

18. SCOTT, A. J.; KNOTT, M. A. A cluster analysis method for grouping meams in the analysis of variance. Biometrics, Washington, v. 30, n. 3, p. 507-512, sept. 1974.

19. TORRES-PENARANDA, A. V. et al. Sensory characteristics of soymilk and tofu made from lipoxygenase-free and normal soybeans. Journal of food science, v. 63, n. 6, p. 1084-1087, 1998.

20. TORRES-PENARANDA, A. V.; REITMEIER, C. A. Sensory descriptive analysis of soymilk. Journal of food science, v. 66, n. 2, p. 352-356. 2001.

21. WANG, H. L. Tofu e tempeh as potential protein sources in the western diet. Journal of the Association Oil Chemistry science, Champaign, v. 61, n. 3, p. 528-534, 1984.

22. WHITAKER, J. R.; FUJIMAKI, M. (Eds.) Chemical deterioration of proteins. Washington: American Chemical Society, 1979.

23. WOLF, W. J.; COWAN, J. C. Soybean as a food source. Cleveland: CRC press, 1975. 